\title{
The effect of aging, nutrition, and exercise during HIV infection
}

This article was published in the following Dove Press journal:

HIVIAIDS - Research and Palliative Care

29 September 2010

Number of times this article has been viewed

\author{
Gabriel Somarriba \\ Daniela Neri \\ Natasha Schaefer \\ Tracie L Miller \\ Division of Pediatric Clinical \\ Research, Department of Pediatrics, \\ Miller School of Medicine, University \\ of Miami, Miami, Florida, USA
}

\begin{abstract}
Medical advances continue to change the face of human immunodeficiency virusacquired immunodeficiency syndrome (HIV/AIDS). As life expectancy increases, the number of people living with HIV rises, presenting new challenges for the management of a chronic condition. Aging, nutrition, and physical activity can influence outcomes in other chronic conditions, and emerging data show that each of these factors can impact viral replication and the immune system in HIV. HIV infection results in a decline of the immune system through the depletion of CD4+ T cells. From initial infection, viral replication is a continuous phenomenon. Immunosenescence, a hallmark of aging, results in an increased susceptibility to infections secondary to a delayed immune response, and this phenomenon may be increased in HIV-infected patients. Optimal nutrition is an important adjunct in the clinical care of patients with HIV Nutritional interventions may improve the quality and span of life and symptom management, support the effectiveness of medications, and improve the patient's resistance to infections and other disease complications by altering immunity. Moderate physical activity can improve many immune parameters, reduce the risk of acute infection, and combat metabolic abnormalities. As people with HIV age, alternative therapies such as nutrition and physical activity may complement medical management.
\end{abstract}

Keywords: HIV replication, aging, diet, nutrition, exercise, immunity

\section{Introduction}

Human immunodeficiency virus (HIV) infection is no longer a disease of the young. It has been suggested that by $2015,50 \%$ of those living with HIV in the United States will be 50 years of age and older. ${ }^{1}$ Similar trends have been appreciated in other developed nations. ${ }^{2,3}$ Reports for underdeveloped nations are limited, but recent data suggest the HIV-infected population over the age of 50 is increasing in some African countries. ${ }^{4,5}$ Advances in antiretroviral (ARV) therapy have improved morbidity and increased longevity for both children and adults. Optimal medical management and enhanced laboratory monitoring for the effectiveness of treatment is also, in part, responsible for longer life expectancy. The face of HIV continues to evolve, and the disease is now considered a chronic condition. For people infected with HIV, more deaths are attributed to non-HIV related causes, ${ }^{6}$ including cardiovascular disease.

Acquisition of HIV can occur during the entire age spectrum from perinatal transmission $^{7}$ to disease acquired through risky behaviors in adolescence and adulthood. ${ }^{8}$ Older individuals are generally not believed to be at as much risk for HIV; however, it has become evident that the incidence of HIV in this population is increasing. ${ }^{1-5}$ 
The acute infection with HIV begins a cascade of nutritional and cardiometabolic events that are similar for many patients (Figure 1). Since the cascade of events may occur across all age groups, many of the treatment goals are similar for all HIV-infected patients - to optimize immune function and to achieve the greatest degree of viral suppression while decreasing morbidity and mortality from secondary illness. ${ }^{9}$

From the initial infection, viral replication is a continuous phenomenon. This process is evident even during the use of highly active ARV therapy (HAART). ${ }^{10} \mathrm{HIV}$ disorders the immune system primarily through depletion of CD4+ $\mathrm{T}$ cells that are fundamental in the development of specific immune responses toward infectious agents. The immune system changes with age. "Normal" immune dysfunction is typically found at either end of the age spectrum both infants and older people are at particular risk. This relative immunodeficient state is further compromised in HIV-infected infants, young children, and older individuals. The older population, most commonly described as anyone with HIV over the age of 50, faces many challenges due to normal changes in the immune system. Aging is associated with immunosenescence that implies the increased susceptibility to infections secondary to a delayed immune response. In addition, older patients have a greater number of comorbidities that may further complicate their health. Thus, age, often, is an independent factor that is associated with impaired immunologic responses.

ARVs have significantly improved morbidity and mortality. ${ }^{11}$ Nutritional abnormalities, including both malnutrition and obesity, are highly prevalent among HIV-infected children and adults and can independently contribute to declines in health and increases in mortality. Weight loss, cachexia, obesity, and cardiometabolic problems are a few of the nutritional factors that increase the risk of death.

Over the past decades, there have been multiple epidemiological studies showing the relationship between physical activity and overall health in non-HIV populations. Physically active adults are less susceptible to viral and bacterial infections when compared with sedentary adults, suggesting that physical activity improves overall immune function. Research evidence supports the findings that exercise decreases ageassociated immunosenescence, ${ }^{12}$ increases innate immune function, ${ }^{13}$ and decreases chronic inflammation. ${ }^{14}$ Physical activity may be important to decrease the effects of some comorbidities such as lipodystrophy by increasing muscle mass, decreasing obesity by decreasing overall adipose tissue, and improving immune function by increasing $\mathrm{T}$ cells.

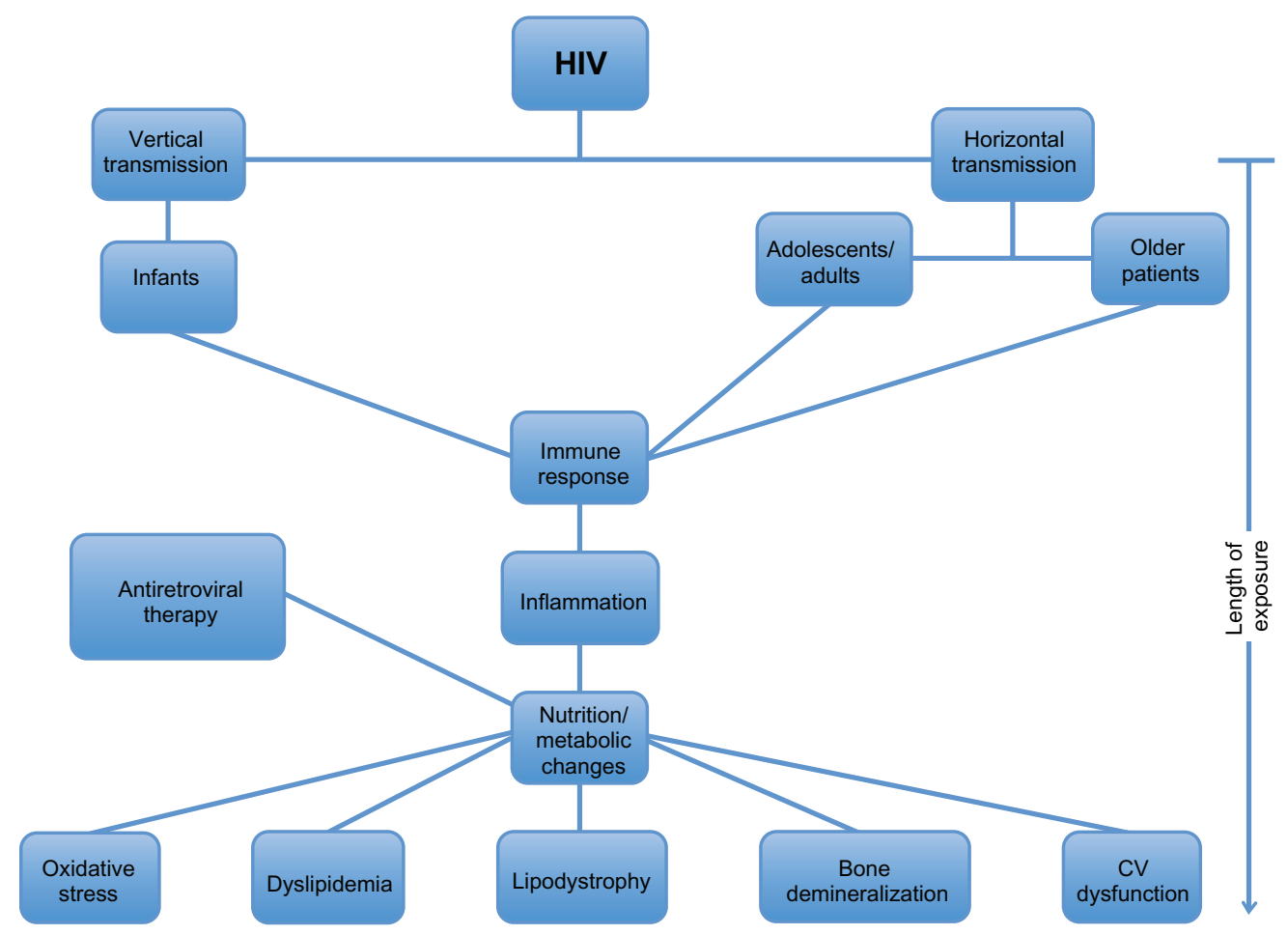

Figure I Nutritional and cardiometabolic events with HIV infection. Abbreviation: CV, cardiovascular. 
This review will investigate how aging, nutrition, and exercise influence clinical and immunological outcomes in HIV infection.

\section{Aging and HIV infection: immunological inferences}

The process of aging produces a functional, biological, and psychological decline in an individual. These changes in total increase the overall risk of disease in older individuals. With aging, the body has a decreased ability to respond to stress, therefore, making a person prone to illness. ${ }^{15}$ The functional capabilities of the immune system decline with aging, and its decrease in capacity may lead to an increased susceptibility to infectious diseases and cancers. ${ }^{16}$ Diminution of immune function with age is associated with a decline in the production of growth hormone, estrogen, dehydroepiandrosterone, and melatonin. ${ }^{17}$ The changes in hormone levels are also associated with age-related degenerative diseases. ${ }^{18}$ It has been postulated that $\mathrm{T}$ and $\mathrm{B}$ cells play a critical role in the development of disorders more commonly seen with older age. ${ }^{19}$

The immune system encompasses innate, humoral, and cellular immunity. The newborn immune system is immature and leads to an increased susceptibility to both viral and bacterial pathogens. ${ }^{20}$ The humoral immune system is underdeveloped in neonates with large dependence on maternally acquired antibodies. ${ }^{20}$ With age, there is a decrease in the functional ability of the natural killer (NK) cells ${ }^{21}$ despite a compensatory increase in the absolute number of NK cells. ${ }^{22}$ Reports have also shown decreases in the number of macrophages and granulocytes, ${ }^{23}$ cells that are important defense against microbes. Finally, proinflammatory cytokines such as interleukin- 6 and intercellular adhesion molecule- 1 are increased with aging and have been associated with morbidity and mortality. ${ }^{24,25}$ Increased levels of immunoglobulins $A$ and $G$ with decreased numbers of B lymphocytes ${ }^{26}$ are most significant among the changes in humoral immunity with aging. The reduced responsiveness and altered antibodymediated defense mechanisms of the humoral immune system associated with senescence lead to an increased risk of disease. Cellular immunity is also affected with aging. Significant decreases are appreciated in $\mathrm{CD} 3+, \mathrm{CD} 4+$, and $\mathrm{CD} 8+$ cells and naïve $\mathrm{T}$ lymphocytes. ${ }^{27}$ These changes point to the decline in immunization response and are predictive of mortality. ${ }^{28}$

With advanced age, many diseases can mimic HIV, therefore, making the diagnosis at times delayed. The majority of older patients are diagnosed with HIV only when they become symptomatic, and the disease has progressed considerably. ${ }^{29}$ There is evidence of accelerated immunosenescence in HIV-infected individuals as they age. The replicative capabilities of the cells of the immune system over a lifetime are limited, even under normal circumstances. ${ }^{30}$ Figure 2 shows the parallels between immunosenescence with normal aging
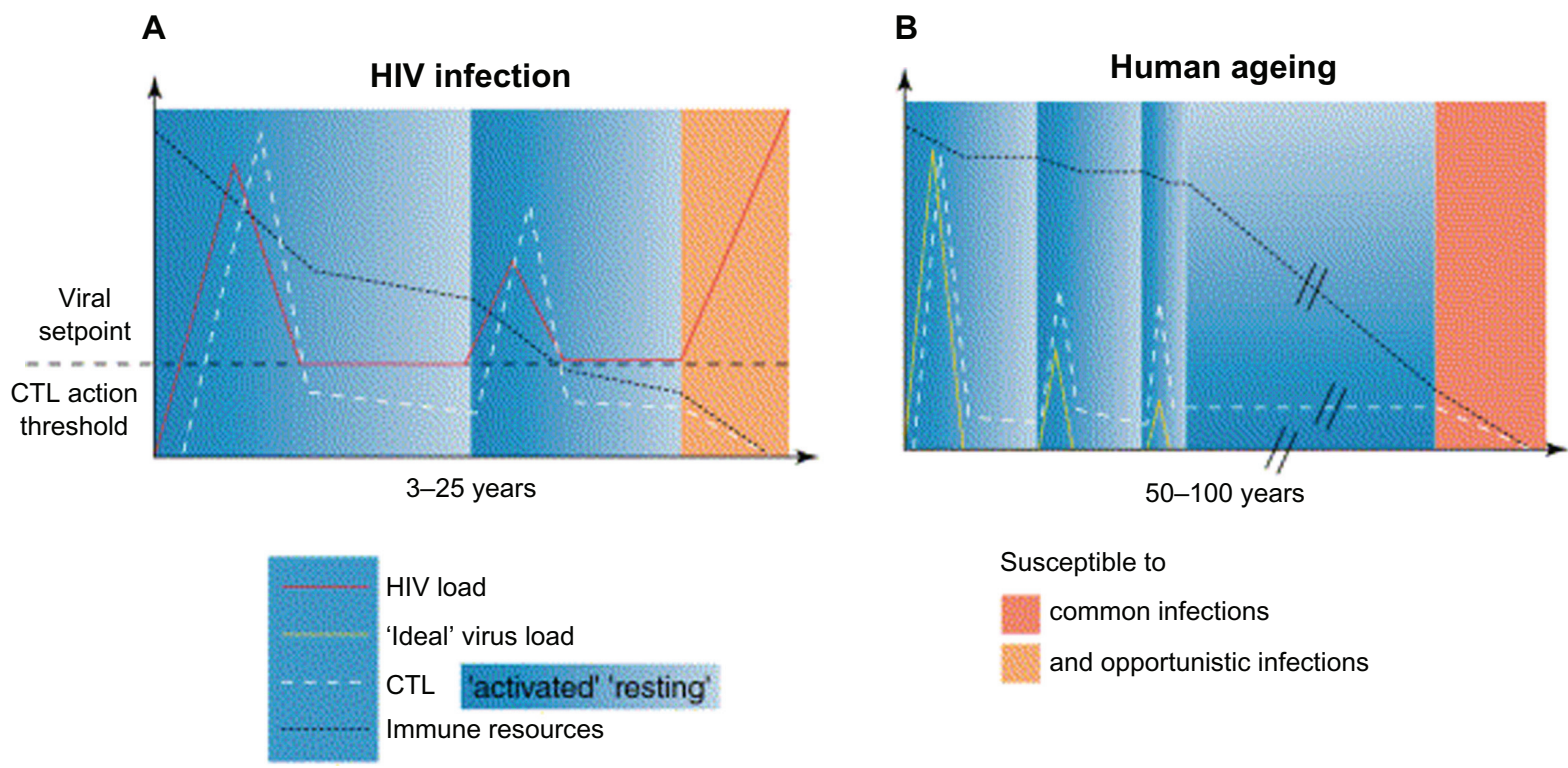

Figure 2 Schematic representation of immunosenescence with normal aging and that with HIV. Copyright (C) 2002 Elsevier. Reprinted with permission from Appay V, Rowland-Jones SL. Premature ageing of the immune system: the cause of AIDS? Trends Immunol. 2002;23:580-585. ${ }^{31}$

Abbreviation: CTL, cytotoxic T-lymphocytes. 
and that with HIV. ${ }^{31}$ Chronic immune activation contributes to the early aging of the immune system in uninfected people. In HIV infection, HIV-specific CD8+ T cells express CD57, a senescence marker, soon after the patient is infected with HIV. ${ }^{32}$ Specific HIV-activated T-cell clones may prematurely reach replicative senescence with loss of CD8+T-cell populations that typically control viral replication. Thus, the normal process of immunosenescence is likely accelerated in HIV.

The impaired renewal of T-cell populations can be caused by a number of factors in HIV infection. The thymus, which typically generates new populations of naïve $T$ cells, undergoes involution and atrophy in HIV-infected individuals. ${ }^{33}$ Furthermore, there may also be a dysregulation of hematopoiesis where there are a lower absolute number of progenitor cells with decreased ability to generate new cells. ${ }^{34,35}$ Overall, the acceleration of immunosenescence in the HIV-infected individual may ultimately place the patient at higher risk of developing disorders associated with further impairment of the immune system (infections, cancers).

Clinically, during the pre-ARV therapy era, studies showed that HIV-infected patients of age 14-24 were anticipated to live 12.5 years on average, whereas those of age 45-54 were expected to live only 7.9 years on average. ${ }^{36}$ In addition, another study determined that the rate of CD4+ cell decline was significantly greater in the older group (over 40 years of age) when compared with the younger group (16-20 years of age). ${ }^{37}$ There is an approximate inverse relationship between CD4+ cell count and survival time in most HIV cases. ${ }^{38}$ The increased rate of CD4+ decline in the older groups may in turn be associated with faster disease progression, and as CD4+ levels reach critical values, viral loads may increase.

The benefits of ARVs in reducing morbidity and mortality for patients with HIV-acquired immunodeficiency syndrome (AIDS) must be balanced against their potential side effects and toxicities. The ideal ARV is one that combines efficacy, adherence, tolerability, yet minimizes viral resistance. ${ }^{39}$ The use of combination ARV therapy typically in the form of HAART can often achieve these goals. Careful followup care is important to prevent potential adverse events and toxicity. ${ }^{40}$ More concerning is the fact that although guidelines for HAART are described for children, adolescents, and adults, ${ }^{41}$ there are no specific guidelines for the older patients with HIV despite the fact that this group is growing.

Older individuals with CD4+ levels below 500 cells/uL are associated with a death rate two times higher than those with a CD4+ of 650 cells $/ \mu \mathrm{L}$ and above. ${ }^{42}$ The older population may be at a disadvantage in maintaining higher CD4+ levels as they have diminished ability to stimulate CD4+ cells as a response to ARVs. A study by Goetz et al ${ }^{43}$ suggested that HIV-infected patients of 55 years and older demonstrated significantly lower CD4+ cell reconstitution when compared with the younger cohort. It has also been noted that persons with reduced immune system function, as found among older individuals, demonstrate a slower response to the effects of HAART. ${ }^{44}$ Therefore, older adults with long-term or new HIV infection can be challenging to manage clinically because of their altered responses to HIV and ARV therapy, owing to decreased immune function that comes naturally with aging but is likely exacerbated by HIV.

\section{Nutrition, HIV, and immune response}

Dietary therapy is an important adjunct in the clinical care of patients infected with HIV. In many conditions, achieving and maintaining optimal nutrition can improve an individual's immune function, reduce the incidence of complications associated with HIV infection, attenuate the progression of HIV infection, improve quality of life, and ultimately reduce mortality associated with HIV. ${ }^{45}$ Multiple strategies to improve nutritional outcomes exist, including ARVs, treatment of coinfections, nutritional counseling, pharmacologic agents to stimulate appetite or anabolism, and nutritional supplements. This section discusses the effects of nutrition therapy on immunologic status and how nutrition may alter the natural course of HIV.

Nutritional complications remain a challenging issue for HIV-infected children and adults in the HAART era and can often contribute to both morbidity and mortality of those infected with HIV. Weight loss, lean tissue depletion, lipoatrophy, anorexia, nutrient malabsorption, diarrhea-induced nutrient losses, and a hypermetabolic state increase risk of death. ${ }^{46}$ In addition, several non-AIDS-related problems such as serum lipid abnormalities, insulin resistance, osteopenia, and increased risk for cardiovascular diseases have emerged since the introduction of HAART.

Several HIV-specific medications, particularly nucleoside reverse transcriptase inhibitors, may inhibit replication of mitochondrial DNA and cause vomiting and diarrhea that may result in the loss of micronutrients. Mitochondrial toxicity may also increase the production of reactive oxygen species, which cause oxidative damage, leading to lactic acidosis. Mitochondrial dysfunction may be responsible for HAART-associated lipodystrophy. ${ }^{47}$ Protease inhibitor therapy has been linked to lipid abnormalities ${ }^{48}$ and changes in cardiovascular risk profiles ${ }^{49,50}$ with decreased brachial artery reactivity $^{51}$ and greater carotid intima media thickness. ${ }^{52}$ 
Although non-nucleotide reverse transcriptase inhibitors are not associated with as many adverse cardiovascular risks, they have their own set of toxicities in other systems. ${ }^{53}$ Patients beginning combination therapy, or HAART, often experience a gain in central adiposity and lean mass over the first 6 months and may develop glucose intolerance, insulin resistance, hyperlipidemia, and peripheral lipoatrophy and decrease in lean mass after 6 months. ${ }^{54}$

Patients who have nutritional and metabolic disturbances that result in weight loss and wasting may show a chronic inflammatory state. Inflammation and other immune responses alter nutritional status through sequestration of minerals (eg, iron and zinc), impaired absorption, increased nutrient loss, or altered nutrient utilization. ${ }^{55}$

Micronutrients are essential for maintaining proper immunologic function. Cellular mechanisms by which trace elements and other nutrients can influence immunity include nutrient effects on protein synthesis, cytokine production, mitosis, apoptosis, and signal transduction. ${ }^{56}$ Micronutrient deficiencies, as a result of acute or chronic inflammation, can persist in the HAART era. Studies suggest low serum levels of retinol, $\alpha$-tocopherol, selenium, and zinc accelerate the progression of HIV to AIDS and death. ${ }^{57,58}$ In certain clinical situations of stress, the production of free radicals is greater than their normal clearance. At that point, the host's endogenous antioxidant system plays a major role to prevent or limit the deleterious effects of free radicals and, in patients with HIV, maintain immune function. ${ }^{58-60}$ Endogenous antioxidants include enzymatic antioxidants (eg, zinc in superoxide dismutase or selenium in glutathione peroxidase), free radical scavengers (eg, vitamins A, C, or E), and metal chelators. ${ }^{61}$ Sources of antioxidants include the diet or the use of specific nutritional supplements. Increased free radical formation and reduced antioxidant defenses can result from a combination of insufficient dietary intake and excessive utilization of specific antioxidants without adequate recycling or replacement. Recognizing and correcting multiple vitamin marginal deficiencies may be the key to the treatment of many HIV-infected patients.

Nutritional status influences the immune system at different levels. Subclinical or frank deficiencies of micronutrients reduce circulating amounts and functional capacities of key immune cells and proteins, including innate immunity and components of adaptive immunity such as T- and B-lymphocyte functions. Other micronutrient deficiencies, including that of essential fatty acids, folate, zinc, and vitamin A, may lead to mucosal lesions or reduced mucosal integrity, thus increasing the risk of infections. ${ }^{62}$
Essential trace elements $(\mathrm{Cu}, \mathrm{Fe}, \mathrm{Se}$, and $\mathrm{Zn})$ can influence immunity due to their presence in metalloenzymes that have key immunologic functions. For instance, zinc is essential for the development of immunity during childhood because of its global role in the normal development and function of cell-mediating innate immunity, neutrophils, NK cells, and macrophages. Among vitamins, vitamin A deficiency reduces lymphocyte response, vitamin $\mathrm{C}$ deficiency depresses cell-mediated immune response, and vitamin $\mathrm{E}$ deficiency impairs $\mathrm{T}$ cell-mediated function and lymphocyte proliferation. Deficiency of any single nutrient may impair resistance to infection, and conversely, infections, even if mild, may result in adverse effect on nutritional status. $^{63}$

The keystones of mounting an effective immune response are rapid cellular proliferation and early synthesis of regulatory and/or protective proteins. Deficiencies of essential nutrients are potentially one of the rate-limiting factors in the development and maintenance of immune responses. A summary of the effects of nutrition interventions on the immune function of HIV-infected patients is described in Table 1.

\section{Macronutrients interventions}

Adequate intake of micronutrients and macronutrients is essential for the restoration and maintenance of body cell mass and normal function, including immunity. The benefits of providing adequate amounts of energy and protein for people living with HIV are clear. ${ }^{73}$

The evidence of the effects of macronutrient interventions in reducing viral load and morbidity and mortality in children and adults living with HIV is sparse. Studies using supplemental formulas, such as those with hydrolyzed or elemental protein and special protein formulas with whey, glutamine, arginine, or high protein content; ${ }^{70}$ lipids including fish oil or n-3 fatty acids $;{ }^{74}$ and fiber interventions, ${ }^{75}$ suggest that macronutrient supplementation may increase energy intake but do not reliably result in increases in fat-free mass, body cell mass, or immunological parameters such as CD4+ count. A cross-sectional study of men with advanced, asymptomatic HIV demonstrated a positive association between protein intake and body cell mass independent of muscle-building activity. ${ }^{76}$ Clark et al ${ }^{70}$ demonstrated that supplementation with specific nutritional supplements, including an amino acid mixture of arginine, glutamine, and $\beta$-hydroxy$\beta$-methylbutyrate, significantly increased body weight and decreased viral load but did not alter energy intake, protein intake, fat mass, or CD4+ count. Although studies have 
Table I Summary of the effects of nutrition interventions on the immune function of HIV-infected patients

\begin{tabular}{|c|c|}
\hline Nutrition intervention & Effects on immune function \\
\hline Antioxidant supplementation - vitamins $\mathrm{A}, \mathrm{C}$, and $\mathrm{E}$ & May decrease oxidative stress and increase oxidative defenses ${ }^{66}$ \\
\hline \multirow[t]{2}{*}{ and selenium } & May increase CD4+ cell count ${ }^{67}$ \\
\hline & Increases concentrations of serum vitamins $A, C$, and $E^{68}$ \\
\hline \multirow[t]{3}{*}{ Selenium supplementation } & Increases serum selenium concentrations ${ }^{69}$ \\
\hline & May reduce the risk of a decrease in CD4+ cell count ${ }^{69}$ \\
\hline & May decrease frequency of hospitalizations ${ }^{69}$ \\
\hline Multiple micronutrient supplementation & May reduce morbidity and mortality ${ }^{81}$ \\
\hline \multirow[t]{2}{*}{ Vitamin D } & May potentiate innate immune response to infection ${ }^{65}$ \\
\hline & May decrease HIV disease progression ${ }^{64}$ \\
\hline Nutritional supplements including an amino acid mixture & May promote increase in CD3 and CD8 lymphocyte counts and \\
\hline of arginine, glutamine, and leucine metabolites, & decrease in the HIV viral load ${ }^{70}$ \\
\hline$\beta$-hydroxy- $\beta$-methylbutyrate & $\begin{array}{l}\text { Promote weight gain, predominantly lean body mass, in HIV+ } \\
\text { patients with muscle wasting }{ }^{70}\end{array}$ \\
\hline \multirow[t]{4}{*}{ Fish oil or $n-3$ fatty acids (EPA and DPA) } & Variations in the ratio of $(n-6):(n-3)$ may modulate \\
\hline & inflammation, clotting, and vascular responses ${ }^{71}$ \\
\hline & Reduces cytokine activity and promotes weight gain in patients \\
\hline & without AIDS-related complications ${ }^{72}$ \\
\hline \multirow[t]{4}{*}{ Optimal nutrition } & May help improve the quality and length of life $\mathrm{f}^{73}$ \\
\hline & Improves symptom management, supports the effectiveness of \\
\hline & medications and other therapies ${ }^{73}$ \\
\hline & $\begin{array}{l}\text { Improves patients' resistance to infections and other disease } \\
\text { complications }^{73}\end{array}$ \\
\hline Combination of ARV drug therapy, appropriate and & May be effective, especially in the treatment of HIV-infected \\
\hline adequate dietary intake, frequent exercise, and a & patients \\
\hline low-dose multivitamin or mineral supplement & \\
\hline
\end{tabular}

Abbreviations: EPA, eicosapentaenoic acid; DPA, docosapentaenoic acid; ARV, antiretroviral.

shown the potential benefits of n-3 fatty acids on immune function for people with HIV, the recommended intake is currently the same as for the general population. ${ }^{77,78}$

\section{Micronutrients interventions}

Micronutrient supplements may provide cellular and clinical benefits for HIV-infected patients on HAART. Growing evidence supports the importance of essential trace elements - particularly copper, iron, selenium, and zinc - for maintaining immune functions. ${ }^{68,69,79}$ However, micronutrient supplementation has shown mixed beneficial effects on immunologic status. ${ }^{80,81}$

A comprehensive review of randomized trials showed that there was no conclusive evidence that micronutrient supplementation (including vitamins $\mathrm{A}, \mathrm{C}$, and $\mathrm{E}$, selenium, zinc) effectively reduced morbidity and mortality among HIV-infected children, adults, and pregnant and lactating women. $^{82}$

Other studies provide additional support for micronutrient supplementation in HIV. Vitamin D deficiency is prevalent in HIV-infected individuals ${ }^{83}$ and is an emerging nutrient that can positively affect immune function, among other important roles. In one study of over 800 women in Tanzania, women with the highest levels of vitamin D had decreased all-cause mortality, HIV disease progression, and anemia. ${ }^{84}$ These effects may, in part, be due to the role of vitamin D in immune regulation. Vitamin D receptors have been found on peripheral blood mononuclear cells, and this suggests vitamin $\mathrm{D}$ can be an immune modulator. ${ }^{64}$ Vitamin $\mathrm{D}$ has also been shown to have an integral role in innate immunity and response to infections such as tuberculosis. ${ }^{65}$

Other investigators have demonstrated that antioxidant supplementation improved some measures of oxidative defense in HIV+ adults on HAART. ${ }^{66,67}$ In another review of randomized clinical trials, Allen et $\mathrm{al}^{81}$ concluded that there is some evidence that supplementation with multiple micronutrients reduces mortality and possibly morbidity, among adults with HIV/AIDS not on HAART. Additional studies are still needed to investigate the effects of multiple micronutrients as an adjunct therapy for people receiving HAART.

Micronutrient supplements may not always prove to be beneficial in HIV-infected individuals. Supplementation with trace elements as single nutrients may lead to micronutrient imbalances, especially in populations with multiple underlying deficiencies. ${ }^{85}$ Both iron deficiency and excess 
iron may inhibit some immune functions. ${ }^{79}$ Likewise with zinc, both deficiency and excessive intake are correlated with reduced CD4 cell counts and survival of the patient with HIV. ${ }^{86}$ High doses of zinc supplementation may lead to zinc-induced copper deficiency ${ }^{87}$ that may further compromise the immune system. Micronutrient supplementation has also been associated with HIV transmission. Randomized trials have shown that maternal vitamin A supplements increase the risk of mother-to-child transmission of $\mathrm{HIV}^{88}$ and can increase mortality in some children born to HIV+ mothers. ${ }^{89}$

There is growing evidence that routine ingestion of a multivitamin or mineral supplement that includes moderate quantities of essential trace elements may result in improvements in immune functions in older people. ${ }^{85}$ However, legitimate use of dietary supplementation is to restore a deficiency. Currently, no conclusive evidence supports the use of dietary supplement solely on the basis of improving infectious outcomes in well-nourished HIV-infected individuals. The World Health Organization promotes and supports adequate dietary intake of micronutrients at Dietary Reference Intakes (DRIs) levels. ${ }^{90}$ It suggests that patients are likely to benefit from consuming a varied diet that is rich in micronutrients. It is likely that HIV-infected patients, particularly those with poor diets or who live in poverty, may benefit from regular consumption of a multivitamin, mineral, and trace element supplement that contains micronutrients at DRI levels.

Good nutrition and nutrition interventions may help improve the quality and length of life, improve symptom management, support the effectiveness of medications and other therapies, and improve the HIV-infected patient's resistance to infections and other disease complications. ${ }^{73}$

\section{Physical activity and immune function}

Over the past few decades, epidemiological studies have demonstrated the relationship between physical activity and overall health. ${ }^{91}$ The Centers for Disease Control and Prevention reports that all ages can benefit from moderate amounts of daily activity ${ }^{87}$ Physical activity has been shown to assist in weight management, lean muscle development, and body fat reduction. ${ }^{92}$ However, in individuals with chronic illness, it is important to determine the effectiveness and safety of physical activity to ensure the benefits outweigh the risks.

Physically active adults are less susceptible to viral and bacterial infections when compared with sedentary adults, suggesting that physical activity improves overall immune function. Scientific evidence suggests that exercise delays age-associated immunosenescence, ${ }^{12}$ increases innate immune function, ${ }^{13}$ and decreases chronic inflammation. ${ }^{14}$ Improved immune function plays a critical role in regulating the inflammatory process, a primary contributor to chronic disease. ${ }^{93}$ Because T-lymphocyte function declines with age, preserving this function with interventions known to improve immunity, such as physical activity, is considered important. ${ }^{13}$ For example, one study in an older population reported that 6 months of aerobic and resistance training at moderate intensity showed significantly increased CD28+ and CD4+ cells, causing an upregulation of the T-helper cells and decreasing the risk of infection. ${ }^{94}$

In addition, physical activity can effectively reduce both acute and chronic inflammation. ${ }^{12}$ A reduction in the chronic inflammatory process, as shown in Figure 1, may inhibit metabolic disturbances and the risk for concomitant diseases. Physical activity can also stimulate the production of hormones. Starkie et $\mathrm{al}^{95}$ demonstrated that the levels of the stress hormones such as glucocorticoids and epinephrine increase with bouts of exercise. The release of these hormones leads to an acute decrease of inflammation. Thus, in addition to the beneficial effect of lowering levels of inflammatory markers, there is evidence that physical activity stimulates production of anti-inflammatory factors as well. ${ }^{96}$

HIV infection dramatically changes the physical wellbeing of an individual, yet the current treatments make it possible for this population to live longer and with greater quality years of life. With this increase in longevity, other chronic conditions are emerging that relate to both normal aging and complications of medical treatments and chronic viral infection. As previously reviewed, individuals with HIV are becoming more susceptible to conditions such as insulin resistance, dyslipidemia, and cardiovascular disease. ${ }^{97} \mathrm{Up}$ to $60 \%$ of HIV-infected patients receiving HAART have body composition and metabolic abnormalities. ${ }^{98}$ HIV-infected patients, including children, ${ }^{99,100}$ have demonstrated positive health and fitness parameters when participating in structured physical activity interventions, including improved overall quality of life. The effects of physical activity on $\mathrm{HIV}$-infected individuals include physical improvements in body composition with decreased waist circumference and waist-to-hip ratio and increased lean body mass, and cardiometabolic fitness - all risk factors for cardiovascular disease. ${ }^{99-102}$

Similar to the general population, HIV-infected patients are at risk for obesity. ${ }^{103}$ Amorosa et al ${ }^{104}$ report a higher prevalence in overweight and obesity compared with wasting that was most prevalent in the pre-HAART era. The prevalence of 
metabolic syndrome among HIV patients is reported between $14 \%$ and $18 \%$ depending on the definition of the diagnosis. ${ }^{105}$ As a result, healthcare professionals suggest exercise as a management strategy to improve lean body mass and cardiovascular fitness and decrease metabolic complications of HIV. Obesity alone can negatively impact immune function. A recent report demonstrated that obese patients had lower levels of CD4 cell counts ${ }^{106}$ and may be associated with slower immunological recovery. Others have shown that obese individuals have higher inflammatory biomarkers and adipokines that may negatively impact the overall function of the immune system. ${ }^{107-109}$ Taken collectively, obese HIV-infected individual may be at a higher risk of immune dysfunction compared with normally nourished patients. Interventions, such as physical activity, that can impact obesity may be beneficial in improving immune function.

Regular physical activity can positively affect the HIVinfected individual psychologically, and emotional wellness has been linked directly related to immune health. Studies have reported a $22 \%-45 \%$ prevalence of depression among HIV-infected people. ${ }^{110}$ This high prevalence indicates that depression is a disease that needs to be assessed in all patients with HIV. Depression has been linked to altering the course of infection due to immune function impairment. HIV-infected patients who participate in regular physical activity have higher life satisfaction scores when compared with those who are sedentary. ${ }^{111}$

The immunological benefits of physical activity, specific to those with HIV infection, include the effects on CD4+ T-lymphocyte counts and HIV viral load. Participants in one study, who participated in aerobic physical activity, showed enhanced production of natural antibodies that, in turn, can potentially delay disease progression. These results suggest that physical activity can positively affect immunological factors that usually cause disease progression in HIV. ${ }^{112}$ Broadbent and Gass ${ }^{113}$ found that 52 weeks of physical activity increases CD4+ and CD25+ percentages in older men. Another study reported an inverse relationship between regular physical activity and viral load, ${ }^{114}$ a finding that had not been previously supported in the literature. However, most reports indicate that exercise does not positively or negatively impact CD4 count or viral load..$^{99,102,115}$ The inconsistency of these results emphasize the need for additional studies that control for the amount and intensity of the physical activity intervention, as well as the stage and progression of the disease. Overall, existing literature indicates exercise interventions are physically and immunologically safe in both children and adults with HIV.
As the evidence for the benefits of physical activity on immune and metabolic functions in persons with HIV grows, recommendations for regular exercise should become an integral part of their care across all ages.

\section{Conclusion}

HIV-infected children and adults are now expected to live longer, but at the same time, they are at risk for developing health complications as a consequence of a life with chronic viral infection, exposures to medications that carry their own toxicities and side effects, and the natural effects of aging on the immune system. Age-related immunosenescence can increase the challenges of controlling viral loads and optimizing CD4+ T-lymphocyte cell counts. Because immunosenescence is an inherent phenomenon that may be accelerated by HIV, strategies that can potentially modify this process should be used. Nutrition therapy may support the effectiveness of the medical treatments by improving cellular function through the supplementation of both macronutrients and micronutrients. Physical activity, known to provide a number of benefits for noninfected individuals, can exert positive effects on metabolic and cardiovascular functions while not imposing deleterious effects on the immune system. Continued research is needed to further define the effects of optimal nutrition and physical activity on the immune system as HIV-infected individuals grow older.

\section{Disclosure}

The authors report no conflicts of interest in this work.

\section{References}

1. Effros RB, Fletcher CV, Gebo K, et al. Aging and infectious diseases: workshop on HIV infection and aging: what is known and future research directions. Clin Infect Dis. 2008;47:542-553.

2. Orchi N, Balzano R, Scognamiglio P, et al. Ageing with HIV: newly diagnosed older adults in Italy. AIDS Care. 2008;20:419-425.

3. Pitts M, Grierson J, Misson S: Growing older with HIV: a study of health, social and economic circumstances for people living with HIV in Australia over the age of 50 years. AIDS Patient Care STDS. 2005; 19:460-465.

4. National AIDS and STD Control Program MoHK. Kenya AIDS Indicator Survey 2007: Preliminary Report. Nairobi, Kenya: Ministry of Health; 2008.

5. Shisana O, Rehle T, Simbayi LC, Parker W, Zuma K, Bhana A, et al. South African National HIV Prevalence, HIV Incidence, Behaviour and Communication Survey. Cape Town, South Africa: HSRC Press; 2005.

6. Brady MT, Oleske JM, Williams PL, et al; for Pediatric AIDS Clinical Trials Group219/219C Team. Declines in mortality rates and changes in causes of death in HIV-1-infected children during the HAART era. J Acquir Immune Defic Syndr. 2010;53:86-94.

7. Volmink J, Siegfried NL, van der Merwe L, Brocklehurst P. Antiretrovirals for reducing the risk of mother-to-child transmission of HIV infection. Cochrane Database Syst Rev. 2007(1):CD003510.

8. Center for Disease Control and Prevention. HIV/AIDS Surveillance Report: Cases of HIV Infection and AIDS in the United States and Dependent Areas, 2007. Atlanta, Georgia: CDC; 2007. 
9. Panel on Antiretroviral Guidelines for Adults and Adolescents. Guidelines for the use of antiretroviral agents in HIV-1-infected adults and adolescents. Department of Health and Human Services. 2009 Dec;1:1-161. Available at http://www.aidsinfo.nih.gov/Content Files/ AdultandAdolescentGL.pdf. Accessed May 7, 2010.

10. Buzón MJ, Massanella M, Llibre JM, et al. HIV-1 replication and immune dynamics are affected by raltegravir intensification of HAART-suppressed subjects. Nat Med. 2010;16: 460-465.

11. Sterne JA, Herman MA, Ledergerber B, et al. Long-term effectiveness of potent antiretroviral therapy in preventing AIDS and death: a prospective cohort study. Lancet. 2005;366:378-384.

12. Woods JA, Vieira VJ, Keylock KT. Exercise, Inflammation, and Innate Immunity. Immunol Allergy Clin North Am. 2009;29:381-393.

13. Kohut ML, Senchina DS. Reversing age-associated immunosenescence via exercise. Exerc Immunol Rev. 2004;10:6-41.

14. Bruunsgaard H. Physical activity and modulation of systemic low-level inflammation. J Leukoc Biol. 2005;78:819-835.

15. Weinert BT, Timiras PS. Theories of Aging. J Appl Physiol. 2003;95: 1706-1716.

16. Srinivasan V, Maestroni GJM, Cardinali DP, et al. Melatonin, immune function and aging. Immunity and Aging. 2005;2:17.

17. Srinivasan V. Melatonin, oxidative stress and neurodegenerative diseases. Aging Cell. 2002;39:668-679.

18. Arlt W, Hewison M. Hormones and immune function: implications of aging. Aging Cell. 2004;3:209-216.

19. Hakim FT, Flomerfelt FA, Boyiadzis M, Gress RE. Aging, Immunity and cancer. Curr Opin Immunol. 2004;16:151-156.

20. Jaspan HB, Lawn SD, Safrit JT, Bekker LG. The maturing immune system: implications for development and testing HIV-1 vaccines for children and adolescents. AIDS. 2006;20:483-494.

21. Ginaldi L, de Martinis M, D'Ostilio A, et al. The immune system in the elderly: III. innate immunity. Immunol Res. 1999;20:117-126.

22. Borrego F, Alonso MC, Galiani MD, et al. NK phenotypic markers and IL2 response on NK cells from elderly people. Exp Gerentol. 1999;34:253-265.

23. Mariani E, Meneghetti A, Neri S, et al. Chemokine production by natural killer cells from nonagenerians. Eur J Immunol. 2002;32: 1524-1529.

24. Straub RH, Miller LE, Scholmeric J, Zietz B. Cytokines and hormones as possible links between endocrinosenescence and immunosenescence. J Neuroimmunol. 2000;109:10-15.

25. Forsey RJ, Thompson JM, Ernerudh J, et al. Plasma cytokines profiles in elderly humans. Mech Ageing Dev. 2003;124:487-493.

26. Ginaldi L, Loreto MF, Corsi MP, et al. Immunosenescence and infectious diseases. Microbes Infect. 2001;3:851-857.

27. Pawelec G, Wagner W, Adibzadeh M, Engel A. T cell immunosenescence in vitro and in vivo. Exp Gerontol. 1999;34:419-429.

28. Olsson J, Wikby A, Johansson B, Löfgren S, Nilsson BO, Ferguson FG Age-related change in peripheral blood T-lymphocyte subpopulations and cytomegalovirus infection in the very old: the Swedish longitudinal OCTO immune study. Mech Ageing Dev. 2000;121: 187-201.

29. Woolery WA. Occult HIV infection: diagnosis and treatment of older patients. Geriatrics. 1997;52:51-61.

30. Appay V, Almeida JR, Sauce D, Autran B, Papagno L. Accelerated immune senescence and HIV-1 infection. Exp Gerentol. 2007;42: 432-437.

31. Appay V, Rowland-Jones SL. Premature ageing of the immune system: the cause of AIDS? Trends Immunol. 2002;23:580-585.

32. Effros RB. Replicative senescence of CD8 T cells: effect on human ageing. Exp Gerontol. 2004;39:517-524.

33. Kalayjian RC, Landay A, Pollard RB, et al. Age-related immune dysfunction in health and in human immunodeficiency virus (HIV) disease: association of age and HIV infection with naive CD8+ cell depletion, reduced expression of CD28 on CD8+ cells, and reduced thymic volumes. J Infect Dis. 2003;187:1924-1933.
34. Marandin A, Katz A, Oksenhendler E, et al. Loss of primitive hematopoietic progenitors in patients with human immunodeficiency virus infection. Blood. 1996;88:4568-4578.

35. Moses A, Nelson J, Bagby GC Jr. The influence of human immunodeficiency virus-1 on hematopoiesis. Blood. 1998;91:1479-1495.

36. Collaborative Group on AIDS Incubation and HIV Survival. Time from HIV-1 seroconversion to AIDS and death before widespread use of highly-active antiretroviral therapy: a collaborative re-analysis. Collaborative Group on AIDS Incubation and HIV Survival including the CASCADE EU Concerted Action. Concerted Action on SeroConversion to AIDS and Death in Europe. Lancet. 2000;355:1131-1137.

37. CASCADE Collaboration. Differences in CD4 cell counts at seroconversion and decline among $5739 \mathrm{HIV}$-1-infected individuals with well-estimated dates of seroconversion. J Acquir Immune Defic Syndr. 2003;34:76-83.

38. Thiebaut R, Pellegrin I, Chene G, et al. Immunological markers after long-term treatment interruption in chronically HIV-1 infected patients with CD4 cell count above 400 x 10 (6) cells/1. AIDS. 2005; 19:53-61.

39. Manfredi R. HIV Disease and Advanced Age: An Increasing Therapeutic Challenge. Drugs Aging. 2002;19:647-669.

40. Carpenter CCJ, Cooper DA, Fischl MA, et al. Antiretroviral therapy in adults: updated recommendations of the International AIDS SocietyUSA Panel. JAMA. 2000;283:381-390.

41. Working Group on Antiretroviral Therapy and Medical Management of HIV-infected Children convened by the National Pediatric and Family HIV Resource Center (NPHRC), the Health Resources and Services Administration (HRSA), and the National Institute of Health (NIH). Guidelines for the use of antiretroviral agents in Pediatric HIV infection. MMWR. 2000;1-59.

42. Phillips AN, Neaton J, Lundgren JD. The role of HIV in serious disease other than AIDS. AIDS. 2008;22:2409-2418.

43. Goetz MB, Boscardin WJ, Wiley D, et al. Decreased recovery of CD4 lymphocytes in older HIV-infected patients beginning highly active antiretroviral therapy. AIDS. 2001;15:1576-1579.

44. Haynes BF, Hale LP, Weinhold KJ, et al. Analysis of the adult thymus in reconstruction of T lymphocytes in HIV-1 infection. J Clin Invest. 1999; 103:453-456.

45. Mahlungulu S, Grobler LA, Visser ME, Volmink J. Nutritional interventions for reducing morbidity and mortality in people with HIV. Cochrane Database Syst Rev. 2007(3):CD004536.

46. American Dietetic Association. Position of the American Dietetic Association and Dietitians of Canada: nutrition intervention in the care of persons with human immunodeficiency virus infection. J Am Diet Assoc. 2004;104:1425-1441.

47. John M, Moore CB, James IR, et al. Chronic hyperlactatemia in HIV-infected patients taking antiretroviral therapy. AIDS. 2001;15: 717-723.

48. Carr A, Samaras K, Chisholm DJ, Cooper DA. Pathogenesis of HIV-1 protease inhibitor-associated peripheral lipodystrophy, hyperlipidemia, and insulin resistance. Lancet. 1998;351:1881-1883.

49. Monforte A, Abrams D, Pradier C, et al; for Data Collection on Adverse Events of Anti-HIV Drugs (D:A:D) Study Group. HIV-induced immunodeficiency and mortality from AIDS-defining and non-AIDS-defining malignancies. AIDS. 2008;22:2143-2153.

50. Fisher SD, Miller TL, Lipshultz SE. Impact of HIV and highly active antiretroviral therapy on leukocyte adhesion molecules, arterial inflammation, dyslipidemia, and atherosclerosis. Atherosclerosis. 2006;185:1-11.

51. Hurwitz BE, Klimas NG, Llabre MM, et al. HIV, metabolic syndrome $\mathrm{X}$, inflammation, oxidative stress, coronary heart disease risk: role of protease inhibitor exposure. Cardiovasc Toxicol. 2004;4:303-316.

52. Maggi P, Serio G, Epifani G, et al. Premature lesions of the carotid vessels in HIV-1-infected patients treated with protease inhibitors. AIDS. 2000;14:F123-F128.

53. Rivero A, Mira JA, Pineda JA. Liver toxicity induced by nonnucleoside reverse transcriptase inhibitors. J Antimicrob Chemother. 2007;59:342-346. 
54. Carr A, Samaras K, Burton S, et al. A syndrome of peripheral lipodystrophy, hyperlipidemia, and insulin resistance in patients receiving HIV protease inhibitors. AIDS. 1998;12:F51-F52.

55. Semba RD, Tang AM. Micronutrients and the pathogenesis of human immunodeficiency virus infection. Br J Nutr. 1999;81:181-189. Review.

56. Sherman AR. Immune dysfunction in iron, copper, and zinc deficiencies. In: Bodgen JD, Klevay LM, editors. Clinical Nutrition of the Essential Trace Elements and Minerals. Totowa, NJ: Humana Press; 2000:309-351.

57. Tang AM, Graham NM, Semba RD, Saah AJ. Association between serum vitamin $\mathrm{A}$ and $\mathrm{E}$ levels and HIV-1 disease progression. AIDS. 1997;11:613-620.

58. Jones CY, Tang AM, Forrester JE, et al. Micronutrient levels and HIV disease status in HIV-infected patients on highly active antiretroviral therapy in the Nutrition for Healthy Living cohort. $J$ Acquir Immune Defic Syndr. 2006;43:475-482.

59. Tang AM, Smit E, Semba RD, et al. Improved antioxidant status among HIV-infected injecting drug users on potent antiretroviral therapy. J Acquir Immune Defic Syndr. 2000;23:321-326.

60. Knox TA, Zafonte-Sanders M, Fields-Gardner C, Moen K, Johansen D, Paton N. Assessment of nutritional status, body composition, and human immunodeficiency virus-associated morphologic changes. Clin Infect Dis. 2003;36 Suppl 2:S63-S68.

61. Gropper SS, Smith I, Groff I, editors. The antioxidant nutrients, reactive species, and disease. Advanced Nutrition and Human Metabolism. Belmont, CA: Wadsworth; 2005:368-377.

62. Cunningham-Rundles S, McNeeley DF, Moon A. Mechanisms of nutrient modulation of the immune response. J Allergy Clin Immunol. 2005;115:1119-1128.

63. Scrimshaw NS, SanGiovanni JP. Synergism of nutrition, infection, and immunity: an overview. Am J Clin Nutr. 1997;66: 464S-477S.

64. Bhalla AK, Amento EP, Clemens TL, Holick MF, Krane SM. Specific high-affinity receptors for 1,25-dihydroxyvitamin D3 in human peripheral blood mononuclear cells: presence in monocytes and induction in T lymphocytes following activation. J Clin Endocrinol Metab. 1983;57:1308-1310.

65. Adams JS, Chen H, Chun R, et al. Substrate and enzyme trafficking as a means of regulating 1,25-dihydroxyvitamin $\mathrm{D}$ synthesis and action: the human innate immune response. J Bone Miner Res. 2007;22 Supp1 2: V20-V24. Review.

66. Batterham M, Gold J, Naidoo D, et al. A preliminary open label dose comparison using an antioxidant regimen to determine the effect on viral load and oxidative stress in men with HIV/AIDS. Eur J Clin Nutr. 2001;55:107-114

67. Jaruga P, Jaruga B, Gackowski D, et al. Supplementation with antioxidant vitamins prevents oxidative modification of DNA in lymphocytes of HIV-infected patients. Free Radic Biol Med. 2002;32: 414-420.

68. Austin J, Singhal N, Voigt R, et al; for the CTN 091/CRIR Carotenoids Study Group. A community randomized controlled clinical trial of mixed carotenoids and micronutrient supplementation of patients with Acquired Immunodeficiency Syndrome. Eur J Clin Nutr. 2006;60:1266-1276.

69. Burbano X, Miguez-Burbano MJ, McCollister K, et al. Impact of a selenium chemoprevention clinical trial on hospital admissions of HIV-infected participants. HIV Clinical Trials. 2002;3: 483-491.

70. Clark RH, Feleke G, Din M, et al. Nutritional treatment for acquired immunodeficiency virus-associated wasting using beta-hydroxy beta-methylbutyrate, glutamine, and arginine: a randomized, doubleblind, placebo-controlled study. JPEN J Parenter Enteral Nutr. 2000; 24:133-139.

71. de Caterina R, Basta G. N-3 fatty acids and the inflammatory responsebiological background. Eur Heart J. 2001;3 Suppl D:D42-D49.
72. Hellerstein MK, Wu K, McGrath M, et al. Effects of dietary n-3 fatty acid supplementation in men with weight loss associated with the acquired immune deficiency syndrome: relation to indices of cytokine production. J Acquir Immune Defic Syndr Hum Retrovirol. 1996;11(3):258-270.

73. Young JS. HIV and medical nutrition therapy. J Am Diet Assoc. 1997; 97(10 Suppl 2):S161-S166.

74. Bell SJ, Chavali S, Bistrian BR, Connolly CA, Utsunomiya T, Forse RA. Dietary fish oil and cytokine and eicosanoid production during human immunodeficiency virus infection. JPEN J Parenter Enteral Nutr. 1996;20:43-49.

75. Schwenk A, Kremer G, Becker K, et al. Enteral nutrition in AIDS cachexia: controlled study on the role of fiber [abstract no. We.B.3262]. Int Conf AIDS. 1996;11:102.

76. Williams SB, Bartsch G, Muurahainen N, Collins G, Raghavan SS, Wheeler D. Protein intake is positively associated with body cell mass in weight-stable HIV-infected men. J Nutr. 2003;133:1143-1146.

77. Food and Nutrition Board, Institute of Medicine. Dietary Reference Intakes for Energy, Carbohydrate, Fiber, Fat, Fatty Acids, Cholesterol, Protein, and Amino Acids. Washington (DC): National Academy Press; 2002:936-967.

78. US Department of Health and Human Services and U.S. Department of Agriculture. Report of the Dietary Guidelines Advisory Committee on the Dietary Guidelines for Americans, 2010. [Updated 2010 July 13]. Available from: http://www.cnpp.usda.gov/DGAs2010-DGACReport. htm. Accessed Jul 29, 2010.

79. Cunningham-Rundles S. Trace element and mineral nutrition in HIV infection and AIDS. In: Bogden JD, Klevay LM, editors. Clinical Nutrition of the Essential Trace Elements and Minerals. Totowa, NJ: Humana Press; 2000:333-351.

80. Drain PK, Kupka R, Mugusi F, Fawzi WW. Micronutrients in HIVpositive persons receiving highly active antiretroviral therapy. Am J Clin Nutr. 2007;85:333-345.

81. Allen LH, Peerson JM, Olney DK. Provision of multiple rather than two or fewer micronutrients more effectively improves growth and other outcomes in micronutrient-deficient children and adults. $J$ Nutr. 2009;139:1022-1030. Epub 2009 Mar 25.

82. Irlam JH, Visser ME, Rollins N, Siegfried N. Micronutrient supplementation in children and adults with HIV infection. Cochrane Database of Syst Rev. 2005;19:CD003650.

83. Mueller NJ, Fux CA, Ledergerber B, et al; for Swiss HIV Cohort Study. High prevalence of severe vitamin D deficiency in combined antiretroviral therapy-naive and successfully treated Swiss HIV patients. AIDS. 2010;24:1127-1134.

84. Mehta S, Giovannucci E, Mugusi FM, et al. Vitamin D status of HIVinfected women and its association with HIV disease progression, anemia, and mortality. PLoS One. 2010;5:e8770.

85. Bogden JD, Oleske JM. The essential trace minerals, immunity, and progression of HIV-1 infection. Nutr Res. 2007;27:69-77.

86. Baum MK, Campa A, Lai S, Lai H, Page JB. Zinc status in human immunodeficiency virus type 1 infection and illicit drug use. Clin Infect Dis. 2003;37 Suppl 2:S117-S123.

87. Food and Nutrition Board, Institute of Medicine. Dietary Reference Intakes for Vitamin A, Vitamin K, Arsenic, Boron, Chromium, Copper, Iodine, Iron, Manganese, Molybdenum, Nickel, Silicon, Vanadium, and Zinc. Washington (DC): National Academy Press; 2002:770-773.

88. Fawzi W, Msamanga G, Hunter D, et al. Randomized trial of vitamin supplements in relation to transmission of HIV-1 through breastfeeding and early child mortality. AIDS. 2002;16:1935-1944.

89. Humphrey JH, Iliff PJ, Marinda ET, et al. Effects of a single large dose of vitamin A, given during the postpartum period to HIV-positive women and their infants, on child HIV infection, HIV-free survival, and mortality. J Infect Dis. 2006;193:860-871.

90. World Health Organization. Nutrient requirements for people living with HIV/AIDS: report of a technical consultation. Geneva: World Health Organization; 2003 May 13-15. 
91. Colbert LH, Visser M, Simonsick EM, et al. Physical activity, exercise, and inflammatory markers in older adults: findings from the Health, Aging and Body Composition Study. J Am Geriatr Soc. 2004;52:1098-1104.

92. Pate RR, Pratt M, Blair SN, et al. Physical Activity and Public Health - a recommendation from the Centers for Disease Control and Prevention and the American College of Sports Medicine. JAMA. $1995 ; 273: 402-407$.

93. Wellen KE, Hotamisligil GS. Inflammation, stress and diabetes. J Clin Invest. 2005;115:1111-1119.

94. Shimizu K, Kimura F, Akimoto T, et al. Effect of moderate exercise training on T-helper cell subpopulations in elderly people. Exerc Immunol Rev. 2008;14:24-37.

95. Starkie R, Ostrowski SR, Jauffred S, Febbraio M, Pedersen BK. Exercise and IL-6 infusion inhibit endotoxin-induced TNF-alpha production in humans. FASEB J. 2003;17:884-886.

96. Jankord R, Jemiolo B. Influence of physical activity on serum IL-6 and IL-10 levels in healthy older men. Med Sci Sports Exerc. 2004;36:960-964.

97. Tanwani LK, Mokshagundam SL. Lipodystrophy, insulin resistance, diabetes mellitus, dyslipidemia, and cardiovascular disease in human immunodeficiency virus infection. South Med J. 2003;180-188.

98. Kosmiski L, Kuritzkes D, Hamilton J, et al. Fat distribution is altered in HIV-infected men without clinical evidence of the HIV lipodystrophy syndrome. HIV Med. 2003;235-240.

99. Miller TL, Somarriba G, Kinnamon DD, et al. The effect of a structured exercise program on nutrition and fitness outcomes in human immunodeficiency virus-infected children. AIDS Res Hum Retroviruses. 2010;26:313-319.

100. Miller TL. A hospital-based exercise program to improve body composition, strength, and abdominal adiposity in $2 \mathrm{HIV}$-infected children. AIDS Read. 2007;17:450-452.

101. Lindegaard B, Hansen T, Hvid T, et al. The effect of strength and endurance training on insulin sensitivity and fat distribution in human immunodeficiency virus-infected patients with lipodystrophy. J Clin Endocrinol Metab. 2008;3860-3869.

102. Souza PM, Jacob-Filho W, Santarém JM, Silva AR, Li HY, Burattini MN. Progressive resistance training in elderly HIV-positive patients: does it work? Clinics (Sao Paulo). 2008;63:619-624.

103. Crum-Cianflone N, Roediger MP, Eberly L, et al; for Infectious Disease Clinical Research Program HIV Working Group. Increasing rates of obesity among HIV-infected persons during the HIV epidemic. PLoS One. 2010;5: e10106.
104. Amorosa V, Synnestvedt M, Gross R, et al. A tale of 2 epidemics: the intersection between obesity and HIV infection in Philadelphia. J Acquir Immune Defic Syndr. 2005;39:557-561.

105. Samaras K, Wand H, Law M, Emery S, Cooper D, Carr A. Prevalence of metabolic syndrome in HIV-infected patients receiving highly active antiretroviral therapy using International Diabetes Foundation and Adult Treatment Panel III criteria: associations with insulin resistance, disturbed body fat compartmentalization, elevated C-reactive protein, and [corrected] hypoadiponectinemia. Diabetes Care. 2007;113-119.

106. Crum-Cianflone NF, Roediger M, Eberly LE, et al; for Infectious Disease Clinical Research Program HIV Working Group. Obesity among HIV-infected persons: impact of weight on CD4 cell count. AIDS. 2010;24:1069-1072.

107. Ford ES, Li C, Sattar N. Metabolic syndrome and incident diabetes: current state of th evidence. Diabetes Care. 2008;31:1898-1904.

108. Bahceci M, Gokalp D, Bahceci S, Tuzcu A, Atmaca S, Arikan S. The correlation between adiposity and adiponectin, tumor necrosis factor alpha, interleukin-6 and high sensitivity C-reactive protein levels. Is adipocyte size associated with inflammation in adults? J Endocrinol Invest. 2007;30:210-214.

109. Lord GM. Leptin as a proinflammatory cytokine. Contrib Nephrol. 2006;151:151-164

110. Berger-Greenstein JA, Cuevas CA, Brady SM, et al. Major depression in patients with HIV/AIDS and substance abuse. AIDS Patient Care and STDS. 2007;21:942-955.

111. Ramírez-Marrero FA, Smith BA, Meléndez-Brau N, Santana-Bagur JL. Physical and leisure activity, body composition, and life satisfaction in HIV-positive Hispanics in Puerto Rico. J Assoc Nurses AIDS Care. 2004; 15:68-77.

112. Veljkovic M, Dopsaj V, Stringer WW, et al. Aerobic exercise training as a potential source of natural antibodies protective against human immunodeficiency virus-1. Scand J Med Sci Sports. 2010;20: 469-474

113. Broadbent S, Gass G. Aerobic training increases the stimulated percentage of CD4+CD25+ in older men but not older women. Eur J Appl Physiol. 2008;103:79-87.

114. Bopp CM, Phillips KD, Fulk LJ, Dudgeon WD, Sowell R, Hand GA. Physical activity and immunity in HIV-infected individuals. AIDS Care. 2004;16:387-393.

115. Roubenoff R, Skolnik PR, Shevitz A, et al. Effect of a single bout of acute exercise on plasma human immunodeficiency virus RNA levels. J Appl Physiol. 1999;86:1197-1201.
HIV/AIDS - Research and Palliative Care

\section{Publish your work in this journal}

HIV/AIDS - Research and Palliative Care is an international, peerreviewed open-access journal focusing on advances in research in HIV, its clinical progression and management options including antiviral treatment, palliative care and public healthcare policies to contro viral spread. The journal welcomes original research, basic science, clinical \& epidemiological studies, reviews \& evaluations, expert opinion \& commentary, case reports \& extended reports. The manuscript management system is completely online and includes a very quick and fair peer-review system. Visit http://www.dovepress.com/ testimonials.php to read real quotes from published authors. 